\title{
Garantir o interesse e a atividade da criança: as festas escolares e o ideário renovado de ensino (finais do século XIX e primeiras décadas do século $\mathrm{XX}$ )
}

\author{
Renata Marcílio Cândido ${ }^{1}$
}

\section{Resumo}

O artigo analisa as relações entre o objeto festas escolares e as ideias escolanovistas divulgadas em periódicos de ensino e manuais pedagógicos publicados em finais do século XIX e início do XX. Trata-se de um relato de pesquisa que busca analisar como as comemorações escolares se relacionaram ao discurso renovado de ensino contribuindo para a consolidação de premissas fundantes do movimento. As análises elaboradas indicam que experiência festiva reconstruída transformar-se-ia na atividade capaz de garantir o interesse e a funcionalidade da educação, reunindo, em um só evento, conceitos caros ao movimento renovador.

Palavras-chave: Festas Escolares, Ideário Renovado, Modernidade Pedagógica.

Ensuring the child's interest and activity: school parties and renewed teaching ideas (late 19th and early 20th centuries)

\section{Abstract}

The article analyzes the relations between the object school holidays and the Escolanovistas ideas published in teaching periodicals and pedagogical manuals published in the late nineteenth and early twentieth centuries. It is a research report that seeks to analyze how the school celebrations were related to the renewed discourse of teaching contributing to the consolidation of the founding premises of the movement. The elaborated analyzes indicate that a rebuilt festive experience would become the activity capable of guaranteeing the interest and functionality of education, bringing together, in one single event, concepts that are dear to the renovating movement.

Keywords: School Holidays, Renewed Idea, Pedagogical Modernity.

\section{Introdução}

A primeira vez que vi o estabelecimento, foi por uma festa de encerramento de trabalhos.

Transformara-se em anfiteatro uma das grandes salas da frente do edifício, exatamente a que servia de capela; paredes estucadas de suntuosos relevos, $e$ o teto aprofundado em largo medalhão, de magistral pintura (...). Desarmado o oratório, construíram-se bancadas circulares, que encobriam o luxo das paredes. Os alunos ocupavam a arquibancada. Como a maior concorrência preferia sempre a exibição dos exercícios ginásticos, solenizada dias depois do encerramento das aulas, a acomodação deixada aos circunstantes era pouco espaçosa; e o público, pais e correspondentes em geral, porém mais numeroso do

\footnotetext{
${ }^{1}$ UNIFESP, São Paulo, renata.candido@unifesp.br.
} 
que se esperava, tinha que transbordar da sala da festa para a imediata. Desta ante-sala, trepado a uma cadeira, eu espiava. Meu pai ministrava-me informações. Diante da arquibancada, ostentava-se uma mesa de grosso pano verde e borlas de ouro. Lá estava o diretor, o ministro do império, a comissão

dos prêmios. Eu via e ouvia. Houve uma alocução comovente de Aristarco; houve discursos de alunos e mestres; houve cantos, poesias declamadas em diversas línguas. $O$ espetáculo comunicava-me certo prazer respeitoso. (Pompéia, 1996, p.16-17) ${ }^{2}$

As festas escolares impressionaram os que dela participaram, deixaram marcas em suas memórias, constituindo-se em eventos de deslumbramento social, cuja potencialidade educativa deveria ser explorada pelos educadores e reformadores da instrução básica de finais do século XIX e início do século XX. Ao descrever o seu primeiro contato com a escola, o menino Sérgio, narrador e protagonista do romance de Raul Pompéia, O Ateneu, 1839 (1996), nos dá indícios importantes acerca do que foram as festas escolares para as crianças que as vivenciaram, em um primeiro momento como espectadores e, depois, como protagonistas. Por meio delas, as crianças poderiam construir uma representação inicial do que significava ser aluno de uma determinada instituição escolar em um contexto social e histórico específico. As solenidades eram ocasiões públicas nas quais os alunos poderiam se apropriar de maneiras diferentes dos espaços e dos saberes escolares, ou seja, atribuindo a essas ocasiões, significados diferentes dos rotineiramente vivenciados.

Neste sentido, o artigo pretende discutir como foram construídas as argumentações que contribuíram para a criação da concepção de festa pedagógica em finais do século XIX e início do século XX, especialmente investigadas a partir dos pedagogos representantes da Escola Nova. Sabe-se que, para compreender-se o discurso pedagógico, faz-se necessária a apreensão de uma trama tecida de discursos provenientes de diferentes campos e agentes (BOURDIEU, 1990, 1996). A escolha dos autores, teve como critério, a incidência dos mesmos nas publicações da época (periódicos e manuais de ensino), assim como a inserção dos mesmos em um projeto mais amplo que pretendeu a instituição da modernidade pedagógica em escolas do mundo todo,

\footnotetext{
2 POMPÉIA, R. O ateneu. 16. ed., São Paulo: Ática, 1996.
} 
prevendo, para todas elas, um mesmo modelo de ensino fundamentado em discursos científicos de áreas distintas, como: a medicina, a psicologia e a própria pedagogia, que então se constituía enquanto ciência (SCHRIEWER; NÓVOA, 2000).

A modernidade pedagógica caracterizou-se por um conjunto de ideias que se organizaram no decorrer do século XIX acerca das melhores formas de instruir e "governar" as novas gerações, considerando o papel fundamental da escola na produção de 'sistemas de governo' (SCHRIEWER; NÓVOA, 2000). O período considerado desde o último quartel de oitocentos até meados do século XX é indicado pelos historiadores da educação como de importância fundamental para a compreensão do processo de arrancada do projeto sociopolítico de escolarização massiva e da constituição de uma unanimidade científico-social representada pelo domínio da psicopedagogia de base experimental e, posteriormente, pelo movimento da Educação Nova das primeiras décadas do século XX (CARVALHO; Ó, 2009).

Mesmo não definindo ou tratando especificamente do termo festas escolares, alguns autores apenas mencionaram a importância de iniciativas desse tipo no âmbito escolar (LIMA, 1914; DEWEY, 1936; CLAPARÈDE, 1933), é possível perceber nos discursos destes educadores justificativas que fundamentaram a proposta e realização das comemorações com diferentes temas nas escolas. Desse modo, busca-se examinar neste artigo quais foram os argumentos teóricos e metodológicos que permitiram a disseminação dessa prática nas escolas públicas paulistas, assim como compreender como as várias premissas enunciadas por educadores como Jonh Dewey, Lourenço Filho, Adolpho Ferrière e Édouard Claparède, representantes selecionados do movimento da Escola Nova, puderam ser realizadas por meio das comemorações escolares.

\section{A atividade e a centralidade da criança nas festas educativas}

As festas apresentaram-se nos textos dos educadores da época como uma atividade de ensino garantidora do interesse e da ação da criança sobre seu processo educativo e, por estes motivos, considerada como facilitadora do aprendizado dos conteúdos e dos valores escolares. Faz-se relevante salientar que a discussão sobre a renovação das metodologias de ensino inseriuse em um projeto mais amplo da instituição da modernidade pedagógica, prevendo para todas 
as instituições de ensino um mesmo modelo de organização e funcionamento fundamentado em discursos científicos de áreas distintas (SCHRIEWER; NÓVOA, 2000). A constituição da pedagogia moderna no século XIX teve como expressão máxima o movimento de renovação educacional intitulado Escola Nova. Tal proposta educacional também foi conhecida mundialmente de forma relacionada a expressões tais como: 'métodos ativos', 'educação centrada na criança', 'autonomia da criança' e 'pedagogias não-diretivas'. Apresentou-se como uma nova forma de conceber a educação e o educando, baseando seus métodos pedagógicos em estudos científicos acerca do desenvolvimento dos aspectos afetivo, social e intelectual da criança (NÓVOA, 1995).

A Educação Nova é o princípio do fim de um 'discurso escolarizante' sobre a educação das crianças. Mas é também o exarcebar da crença nas potencialidades da escola (de uma outra escola, claro) [...]. Nunca ninguém desconfiou tanto da escola e nunca ninguém acreditou tanto na escola como os grupos que deram corpo e voz à Educação Nova (NÓVOA, 1995, p.31).

Fundamentada em teorias das áreas da psicologia e da sociologia, a proposta renovada concebeu o ensino baseado nas atividades e nas necessidades da criança, condição primeira na organização das atividades escolares. Nas palavras de Adolpho Ferrière (1934), a escola ativa deveria ser, antes de tudo e de uma forma geral, a aplicação das leis da psicologia à educação das crianças: "dum lado, a sociologia, e doutro lado, a psicologia genética estudando o desenvolvimento dos seres, eis as ciências-mães desta ciência aplicada ou desta arte que é a educação" (FERRIÈRE, 1934, p.V). O aprendizado real e efetivo só seria possível, na visão destes autores, com a participação e envolvimento da criança em todo o processo educativo - "o verdadeiro meio de direção, ou controle social das atividades dos educandos, é a sua participação com outras pessoas em atividades comuns, cujo sentido e finalidade eles adotem plenamente" (DEWEY, 1936, p.24). Ao educando não era mais requerida a passividade da escola tradicional, mas sim uma atuação ativa em todas as realizações escolares de modo a possibilitar o pleno desenvolvimento de suas capacidades cognitivas, psicológicas e sociais.

A aprendizagem concebida na perspectiva do ensino ativo consistia na aquisição gradual e individual de habilidades por cada criança, que deveria ser levada a aprender, pelo seu educador "vigilante" e perspicaz, capaz de garantir o meio e mobilizar os interesses dos seus educandos. Para cada educando deveria ser assegurado os recursos para aprender por meio da 
observação, da pesquisa, do trabalho, da construção, do pensamento e da resolução de situações problemáticas relacionadas à sua própria vida. Fazia-se necessário, desse modo, oferecer, no ambiente educacional, oportunidades para que os alunos sentissem a necessidade e o interesse em resolver situações difíceis, aprender com estas situações e por fim, resolvê-las pelo seu próprio esforço (LOURENÇO FILHO, 1963). O envolvimento total da criança na atividade educativa deveria ser capaz de desenvolvê-la integralmente, garantindo não somente o aprendizado dos conteúdos das diferentes disciplinas, mas também de atitudes e de valores relacionados ao ato de aprender. $O$ interesse nas atividades escolares seria mantido pela retomada e problematização de situações da própria vida da criança, tanto intelectual quanto social.

O termo atividade, considerado como o eixo articulador entre o ensino e aprendizagem na nova proposta de ensino, esteve presente em quase todos os estudos dos distintos pedagogos escolanovistas, que atribuem ao conceito um significado distinto do utilizado nos moldes tradicionais. Segundo esses teóricos, o conceito atividade já estaria presente nas metodologias de ensino tradicionais, o que não queria dizer que essas escolas fossem ativas, já que para receberem essa denominação, a atividade do educando deveria ocupar o lugar central no ensino e ser compreendida na sua acepção mais completa, ou seja, nos seus dois sentidos complementares assim como propunha Claparède (1933): o primeiro sentido do conceito estaria relacionado ao caráter funcional do termo; é uma ação ou reação que corresponde a uma necessidade, despertada por um desejo e tendo como ponto de partida o indivíduo que age. Já a segunda acepção da palavra 'atividade', relacionar-se-ia a ideia de efetivação, expressão, produção, processo centrífugo, mobilização de energia, trabalho. Aqui, atividade se opõe a recepção, ideação, sensação, impressão e imobilidade" (CLAPARÈDE, 1933, p.196). As atividades festivas, compreendida de forma mais ampla, apresentaria como ponto de partida a ação dos diferentes indivíduos (professores e alunos), instigada por interesses e necessidades, e deveria contribuir, a partir dos seus processos de elaboração e concretização, para o aprendizado ativo do educando.

As duas acepções se complementariam, mas a segunda sem a primeira não foi característica da escola ativa. O primeiro sentido estava associado às ideias de necessidade, interesse, desejo, disciplina interior, móveis interiores, consentimento do indivíduo, 
espontaneidade, liberdade e atenção espontânea. Já o segundo, significou expressão, produção (ou reprodução), exteriorização, reação, processo centrífugo, invenção, movimento, trabalho (escola-oficina), ambas contrárias à ideia de desgosto, indiferença, disciplina exterior, móveis extrínsecos, resistência, constrangimento, obediência, desatenção, atenção voluntária (com esforço), processo centrípeto, imobilidade, leitura (escola livresca) da escola tradicional; que não estaria completamente desprovida da atividade do aluno, mas somente não a compreendia de forma tão abrangente como indicavam os pedagogos renovados. Sendo assim, não foram todas as atividades escolares que se transformaram em aprendizado eficaz para os educandos (CLAPARÈDE, 1933).

A atividade dos alunos não basta para tornar uma escola 'ativa', enquanto não se tiver dado à palavra 'atividade' o seu sentido completo. A palavra 'ativo' é uma palavra vaga. Para muitos 'ativo' quer dizer que se move, se agita, que executa um trabalho, que escreve, que desenha, que faz alguma coisa em lugar de se limitar a escutar. [...] Pergunto-me, porém, (peço perdão ao meu amigo Bovet que o formulou por primeiro) se o termo 'escola ativa' não é também ambíguo. Figura-se que ativo significa 'que age exteriormente'; que a atividade desenvolvida é proporcional ao número de atos visíveis executados. Ora, digo que um indivíduo que pensa, sem se mexer no fundo de sua cadeira, pode ser muito mais ativo do que um aluno que faz uma tradução de latim (CLAPARÈDE, 1933, p.186).

Para se transformar em aprendizagem, a atividade deveria ser planejada e controlada, no sentido de garantir a melhor reflexão da experiência vivida para o educando. Aqui se apresenta uma problemática instigante: como garantir o interesse da criança em uma atividade controlada por outros? Neste caso, o meio direto de controlar ou de governar a educação seria "o de preparar o ambiente que a criança age, pensa e sente" (DEWEY, 1978, p.19). Em um ambiente previamente organizado, a criança tem a oportunidade de realizar todas as suas experiências e retirar delas o maior proveito possível. A experiência educativa consiste em uma experiência inteligente, na qual participa o pensamento e existe a possibilidade de percepção das relações e continuidades não percebidas: "todas as vezes que a experiência for assim reflexiva, isto é, que atentarmos no antes e no depois do seu processo, a aquisição de novos conhecimentos, ou conhecimentos mais extensos do que antes, será um dos seus resultados naturais" (DEWEY, 1978, p.07). Em outras palavras, a realização de atividades previamente organizadas acarretaria 
"naturalmente" o aprendizado pleno de todos os estudantes.

As festas escolares como experiência educativa deveria garantir por meio da participação e atividade do aluno, o efetivo aprendizado tanto dos conteúdos escolares, quanto das normas e dos valores implícitos nos temas de cada festa. Neste sentido, a festa alargava-se para antes e depois do próprio ato, de dois modos distintos e complementares: em um momento anterior representado pelo conhecimento que a festa exigia acerca dos modos próprios de organizá-la (previsto nos regulamentos, circulares, experiências escolares anteriores), no estudo dos temas das festas e suas relações com os outros saberes curriculares, bem como o seu significado para a vida escolar e social.

Na organização duma festa escolar deverão tomar parte todos os alunos. E para não alimentar vaidades nem quebrar estímulos, não deverá o professor marcar despoticamente atribuições pessoais nos trabalhos de organização. Deixará que a classe se manifeste livremente sobre a distribuição de funções, para ele só depois objetar no que tiver por conveniente. Tendo ouvido as opiniões dos próprios alunos, ficará o professor mais apto a acertar na distribuição dos papéis. Depois duma festa escolar deverá o professor organizar trabalhos práticos com ela relacionados, à maneira do que fez em relação aos passeios e excursões escolares (LAGE, 1945, p.203-204).

E, após o evento, seu efeito poderia ser percebido na disseminação das notícias nos jornais e periódicos que buscaram traduzir em palavras o ato festivo e nas lembranças daqueles (as) que dela participaram. A própria festa enquanto experiência poderia ser considerada por si só educativa: "o fim (resultado) da educação se identifica com seus meios (o processo), do mesmo modo, aliás, que os fins da vida se identificam com o processo de viver" (DEWEY, 1978, p.08). Como evento social, as comemorações sempre fizeram parte da vida do ser humano e na escola não deveria ser o contrário.

No dia nove de agosto passado inaugurou-se na cidade de Bragança o grupo escolar criado pelos constantes esforços do distinto inspetor escolar Sr. Raphael de Lima.

A cerimônia da inauguração foi feita com grande regozijo da população, que via naquele ato a garantia de um ensino mais metódico do que se dá nas escolas isoladas.

Parabéns ao povo de Bragança e ao digno inspetor pelo novo melhoramento (A ESCHOLA PÚBLICA, 1897, p.277). 
No âmbito da Escola Nova, a criança foi considerada na sua integralidade e as atividades escolares deveriam desenvolver o máximo possível todas as capacidades dos educandos. Era necessário, ainda, conservar e desenvolver as energias úteis e construtivas do aluno para fazer dele uma personalidade autônoma e responsável (FERRIÈRE, 1934, p.V). Acredita-se que tudo que se ensina de fora ou se impõe ao educando, sem contato com as energias interiores, tende a desequilibrar e a prejudicar o ser e por este motivo a escola ativa procurou fazer predominar o espírito, isto é, a intuição, o coração, a razão e a vontade na sua essência qualitativa no processo educativo.

As festas escolares foram apresentadas como atividades educativas exemplares da concretização das premissas renovadas que colocam o educando no lugar central no processo de ensino e aprendizagem, capaz de ao mesmo tempo desenvolvê-lo cognitivamente e emocionalmente. Ela deveria ser a ocasião privilegiada para o educando ser visto e se fazer ver, de incitar o interesse da criança pelo evento que estava sendo comemorado, despertar seu intelecto, seus sentimentos e suas emoções. Além disso, ainda foi possível perceber a consideração do desenvolvimento infantil como um todo. As crianças sentiriam maior interesse em realizar atividades autênticas e que trariam a marca da responsabilidade, sendo que sua participação foi considerada a única forma capaz de integrar o educando à escola no sentido de levá-lo a querer e viver a vida escolar:

As atividades extraclasses propiciam essa possibilidade, uma vez que funcionam sob responsabilidade do educando, com base na participação em empreitadas comuns com seus colegas e professores, instituições sociais e pessoas outras da comunidade, em atividades de verdade, que podem ser apreciadas como contribuições efetivas para a vida escolar e social (NÉRICl, 1960, p.413).

$\mathrm{Na}$ maior parte dos programas festivos, existiram horários específicos para a demonstração do desenvolvimento intelectual, por exemplo, nos exames, nas recitações de poesias, e física nas apresentações de ginástica, além de todo o controle emocional que a autodisciplina nestes eventos demandava. Valorizava-se a autonomia das crianças, que eram ensaiadas durante longos períodos, em alguns casos durante todo o ano escolar, e tomavam para si a responsabilidade pelo desenvolvimento e bom andamento da festa. Os hinos, as poesias, os textos, os discursos buscavam incitar o espírito, isto é, a intuição, o coração, a razão e a vontade 
na sua essência qualitativa, assim como propunha o movimento. Além disso, a realização de uma festa dependia sempre do interesse e da atividade do aluno, principal protagonista do evento, dependendo dele o seu sucesso. A experiência festiva reconstruída e reorganizada transformarse-ia na atividade capaz de garantir o interesse e a funcionalidade da educação, reunindo em um só evento conceitos caros ao movimento renovador.

As comemorações escolares, assim como a educação, deveriam ter um valor funcional (CLAPARÈDE,1933), ou seja, ser capaz de desenvolver os processos mentais considerando-os, não somente em si mesmos, mas também quanto a sua significação biológica, à sua utilidade para a ação presente ou futura, ou seja, para a vida. A "educação funcional é a que toma a necessidade da criança, o seu interesse em atingir um fim, como alavanca da atividade que se Ihe deseja despertar!" (CLAPARÈDE, 1933, p.02). A sua funcionalidade não poderia ser resumida na sua atratividade, já que nem tudo que se faz atraente possui um valor educativo, mas naquela que teria utilidade. Infere-se a partir das considerações deste autor, que as festas escolares, ao mesmo tempo em que deveriam ser atrativas e garantir o envolvimento e participação de todos os autores escolares, deveriam ser permeadas pelo seu caráter educativo.

As festas assumiriam a função de autonomizar a criança, quando ela deixava de ser o mero espectador e tornava-se o protagonista do seu aprendizado, o responsável pelo sucesso do "teatro da festa". A centralidade da criança nas festas é reconhecida em solenidades dedicadas exclusivamente a elas, como aconteceu nas denominadas "festas das crianças" levadas a efeito nas décadas de 1920 e 1930, período que poderíamos considerar de consolidação dos ideais renovados.

No Brasil, as notícias e comentários sobre as festas das crianças concentram-se nas páginas da Revista Escolar, que circulou no contexto educacional paulista entre os anos de 1925 e 1927 e está associada à divulgação dos princípios da escola nova nesse contexto. Ao todo são registrados cinco textos do mesmo periódico, do qual se destacam alguns. O primeiro trata da comemoração do dia 12 de outubro, já instituído "Dia da Criança", no Teatro Municipal de São Paulo para um público composto de três mil crianças das nossas escolas, onde

O palco será adaptado de moda a bem acomodar tão numeroso corpo de cantores, talvez o maior que se tenha organizado até aqui. O programa, otimamente organizado, é todo composto de músicas de reputados autores brasileiros, adaptadas às vozes infantis [e seria] de prever o brilhantismo da

Periódico Horizontes - USF - Itatiba, SP - Brasil - e021016 
festa, dada a competência do seu organizador, o maestro João Gomes Junior, inspetor especial de música nas escolas públicas do Estado, [que não havia poupado] esforços no sentido de conseguir os mais surpreendentes efeitos corais e a maior disciplina musical do conjunto" (REVISTA ESCOLAR, 1926, p.86).

A associação feita entre o sucesso do evento e os esforços do professor para a organização e ensaio do coral de crianças indica a contradição sobre a questão do interesse da criança e a realização das atividades escolares. Apesar de caracterizar-se uma festa da criança, a sua participação é restrita a execução de cantos previamente escolhidos e, ainda quem sabe, sofridamente ensaiados pelos alunos com o mestre. Às crianças, muitas vezes, caberia uma participação passiva, restrita ao programa e com poucas oportunidades de livre expressão, como reivindica o artigo intitulado "Conceito Infantil":

Isto é que me dá raiva! Esta coisa é que me dana! Já viram que espalhafato numa festa tão brilhante?!

E dizem:- Festas das Crianças! ...Eu sou criança. Sou pequeno. Na minha cachola pequenina, só tenho gravado: - papai, mamãe; dê-me um tostão, papai; dê-me um doce, mamãe. E, mesmo assim, venho para a minha festa sem caber na pele, de alegria. Mas, chego aqui, dou com meus coleguinhas a recitar versos e poesias de Coelho Netto, Olavo Bilac ... Não sei de quem mais. Por isso ouvi D. Francisca perguntar ao Dr. Francisco se ele entendeu o que disse o Chico ... Versos!... Não entendo patavina! Nem a prosa entendo!... Poetas!... São uns aborrecidos. Não os entendo. Não gosto deles! ... Não gosto, mesmo. Também não gosto do Lulú, quando me ganha as bolinhas. Poetas!... Se eles falassem a minha língua! ... Fizessem versinhos alegres, e eu gostaria deles. Gostaria deles, tanto como da minha professora, porque fala a minha língua para que eu possa entendê-la...

Ora também eu não hei de ser sempre pequeno! E quando eu for gente, entrarei para a academia dos poetas. Serei poeta para vingar-me dos poetas. Farei versos que eles não entendam (REVISTA ESCOLAR, 1927, p.62-63).

O pensamento infantil registrado nas linhas acima assinala a pouca compreensão que as crianças tinham de alguns momentos da festa, para a criança acima não faria sentido em uma festa para crianças recitar versos e poemas de autores, algumas vezes, desconhecidos e que não produziam para elas. Apesar da importância do conteúdo escolar, a situação da festa, segundo o autor, não seria própria para isso. A transcrição desse comentário nas páginas da revista indica a percepção de que deveria existir uma preocupação maior com a compreensão infantil na realização das atividades festivas. Uma festa para as crianças deveria contar com atividades organizadas e levadas a efeito de acordo com a concepção que as mesmas teriam sobre comemoração. 
Considerando as fontes e a potencialidade das festas para a concretização dos princípios educativos da Escola Nova, é preciso ponderar a centralidade das crianças nos eventos comemorativos. A participação das crianças constitui-se condição imprescindível para a organização e realização de qualquer festa que se deseja escolar, entretanto, essa participação pode ser categorizada de duas formas: uma participação passiva, quando elas atuariam como coadjuvantes do evento, seguindo e imitando tudo o que estava previamente acordado e que fora ensaiado com o mestre; ou ativamente como protagonistas da festa, com a liberdade de criação garantida para composição de canções, textos, realização de homenagens, apresentações físicas e teatrais e demonstração dos seus saberes; neste caso, o interesse pela atividade festiva seria real. Seja por meio de uma participação mais ativa ou mais passiva, ou as duas em um mesmo evento almeja-se que, assim como as outras atividades escolares, as festas garantam o aprendizado escolar.

\section{Interessar e ensinar: premissas fundantes das festas escolares}

A concretização do aprendizado na proposta renovada aconteceria também mediante a garantia do interesse do educando pela atividade educativa a ser realizada. As festas foram evocadas em diferentes momentos por diferentes educadores para a garantia deste interesse, seja o interesse pela própria atividade festiva, seja pelo aprendizado de determinado conteúdo de ensino relacionado a essa ocasião, ou ainda, do interesse da sociedade pela escola. O interesse do educando, suas atividades espontâneas, manuais e construtivas, suas afeições e gostos dominantes, deveria constituir-se o ponto de partida da educação (FERRIÈRE, 1934); nenhuma atividade educativa deveria ser desenvolvida sem considerar-se, no âmbito psicológico, tal interesse (DEWEY, 1978).

O interesse, tal como compreendiam os pedagogos da escola renovada, deveria surgir da própria vida do aluno, das experiências vividas rotineiramente; tudo que estaria intrinsecamente ligado à vida consciente e aos conteúdos e sentimentos da vida cotidiana poderiam ser do interesse do educando. Quando existe interesse, empenhamo-nos ativamente em alguma atividade ou pensamento. Ele pode ser concebido como algo dinâmico e pessoal, que deve nos ligar diretamente a uma coisa que tem importância para nós: "por isso, além dos seus aspectos de atividade e de objetividade, possui um aspecto emocional e pessoal" (DEWEY, 1978, p.96). 
Se a matéria das lições tiver um lugar apropriado na expansão natural da consciência da criança; se ela nascer naturalmente das atividades, dos pensamentos e dos próprios sofrimentos da criança, para servir a novas atividades e novos pensamentos, então não haverá necessidade de truques e artifícios de método para tornar o assunto 'interessante' (DEWEY, 1978, p.76).

Os interesses poderiam mudar no decorrer da vida escolar do educando conforme o seu amadurecimento, ou ainda com relação às suas preferências, bem como nas relações com o seu contexto histórico e social. Ao educador renovado sugeria-se a não proposição de atividades preconcebidas, mas a possibilidade de que os alunos, "livremente" escolhessem suas atividades, pois somente assim se formaria o sentimento da disciplina, ou "o hábito de lidar com coisas sérias, tão necessário à vida futura da criança" (DEWEY, 1978, p.87).

Se em alguns autores, percebia-se a indicação vaga das atividades a serem desenvolvidas pelos alunos de acordo com os seus interesses, ou seja, as atividades mudariam de escola para escola e de educando para educando, em outros, as sugestões já seriam mais explícitas. Este seria o caso das produções do pedagogo Adolpho Ferrière (1934), que concebeu o interesse como a força propulsora da atividade educativa que, organizada de forma atraente e diversificada pelo educador, poderia impedir a fadiga escolar e a distração e garantir o desenvolvimento de todas as faculdades do educando: "fazei-a alternadamente observar, anotar, experimentar, desenhar, construir, discutir, resumir oralmente, redigir, corrigir, e as horas passarão rápidas e alegres" (FERRIÈRE, 1934, p.110).

Ao mesmo tempo em que a atividade festiva deveria ser interessante, por ser uma atividade diferente das rotineiramente realizadas no cotidiano escolar, esperava-se que essas garantissem o interesse para outras questões escolares. Não era incomum, em manuais escolares escritos por educadores na época, orientações sobre as formas de organizar as festas e a utilidade que as mesmas possuiriam para o desenvolvimento do processo de ensino.

Nada mais belo do que uma festa de crianças das escolas, reunidas em um jardim ou em um parque, sob às vistas dos professores, ora obedecendo à disciplina a que se habituaram nas classes, ora em plena liberdade entregandose aos folguedos próprios da infância e confraternizando com os coleguinhas de outras escolas (REVISTA DE ENSINO, 1906, p.781). 
A recreação não deveria ser o único fim da comemoração, mas também o ensino, e "isto obriga o professor a uma escrupulosa seleção dos motivos das festas. Devem merecer preferência os motivos patrióticos, morais e sociais, ficando em segundo plano, os de natureza científica, técnica etc." (LAGE, 1945, p.203-204). As festas garantiriam, desse modo, suas funções pedagógicas, "visto proporcionar uma excelente oportunidade de ensinar muitas noções úteis, a rir, a brincar ou a cantar" (VIANA, 1960, p.396). Durante o período de preparação das festas, os educandos poderiam aprender literatura, história e geografia "(matérias relacionadas com as poesias, monólogos, diálogos, etc., que fazem parte do programa); música (pelo menos educam o ouvido); estudariam a pronúncia exata das palavras, e até poderiam adquirir maneiras menos grosseiras" (VIANA, 1960, p.396). Ou seja, é possível assinalar que o conceito de festa, para os escolanovistas, era composto das suas duas funções principais: recreativa e pedagógica.

Em qualquer modalidade de festas, o aluno já teria um comportamento melhor do que o dos recreios escolares. Nestas ocasiões, ele sentiria a responsabilidade de ter de mostrar as habilidades adquiridas nos ensaios, e demonstrá-las de forma satisfatória para o público que o prestigiava. Os professores, sabendo aproveitar este fato, conseguiriam, até mesmo nos casos de alguns alunos cujo interesse pelo estudo era fraco, a melhora substancial do desempenho escolar. Para isso, bastaria que os professores soubessem equilibrar o interesse dos alunos e o aprendizado por meio das solenidades, não consentindo que o interesse pela festa se sobrepusesse aos estudos.

O professor que organize qualquer festa escolar, deve dispor de três qualidades fundamentais: paciência, prudência e persistência. A festa escolar deve dignificar a Escola; de maneira alguma deve transigir com os gostos da multidão, caindo na palhaçada ou na bobice. Por outro lado, os programas devem ser curtos. Os pedagogos recomendam festas que não excedam cinquenta minutos. É preferível efetuar três ou quatro festas pequenas, do que uma festa de três ou quatro horas. Em conclusão: 'a festa escolar é um meio de ação que oferece um certo interesse, mas do qual não convém abusar'. (LOUREIRO, 1950, p.210)

A retomada de alguns dos argumentos elaborados no âmbito da pedagogia renovada acerca do processo de ensino e aprendizagem corrobora a tese das festas escolares como atividades educativas e não somente de divertimento escolar. E possível perceber em teorias como a importância do interesse do aluno para a eficiência do aprendizado, da atividade como 
o centro do processo educativo, da concepção de educação na sua funcionalidade, da corresponsabilização dos educandos pelo sucesso do ato festivo, da aproximação sociedade e escola, das relações entre os saberes curriculares e os diferentes modos de ensiná-los, distintos elementos capazes de delinear o projeto pedagógico das comemorações no âmbito escolar.

\section{Considerações finais}

Desde que foi constituída como um dos objetos privilegiados da cultura escolar (JULIA, 2001), regida por normas e efetivada por práticas, as festas escolares serviram a diferentes e relevantes propósitos para os projetos políticos e educacionais brasileiros. Se em um primeiro momento, serviram para legitimar e divulgar os feitos políticos no âmbito educacional, celebrando as inaugurações e aniversários das escolas públicas paulistas construídas nos primeiros anos da República brasileira, como pudemos depreender das análises das notícias publicadas no periódico A Eschola Publica (1893-1897), em momentos posteriores e, também por meio da divulgação em periódicos educacionais, vimos as festas relacionadas à fundamentação teórica do escolanovismo, especialmente nas publicações: Revista de Ensino (1902-1918) e Revista Escolar (1925-1927). Ou seja, o mesmo objeto, festas escolares, é retomado, nos idos anos 20 do século XX, para fundamentar e disseminar o ideário renovado de ensino. Associada à garantia do interesse e da atividade da criança serviria à concretização das ideias renovadas para o ensino, assim como para a divulgação das mesmas.

\section{Referências}

A ESCHOLA PÚBLICA. Edição de 15 de setembro de 1897. Typ. da Industrial de São Paulo, São Paulo, 1893-1987.

BOURDIEU, P. Coisas ditas. São Paulo: Brasiliense, 1990.

BOURDIEU, P. Razões práticas: sobre a teoria da ação. São Paulo: Papirus, 1996.

CARVALHO, L. M.; Ó, J. R. Emergência e circulação do conhecimento psicopedagógico moderno (1880-1960): estudos comparados Portugal - Brasil. Lisboa: Educa, 2009.

CLAPARÈDE, E. A educação funcional. São Paulo: Companhia Editora Nacional, 1933. (Biblioteca 
Pedagógica Brasileira, Atualidades Pedagógicas, s.III, v.IV).

DEWEY, J. Democracia e educação. São Paulo: Companhia Editora Nacional, 1936. (Coleção Atualidades Pedagógicas).

DEWEY, J. Vida e educação. São Paulo: Companhia Editora Nacional, 1978. (Coleção Atualidades Pedagógicas).

FERRIÈRE, A. A escola ativa. Porto: Editora Nacional de Antônio Figueirinhas, 1934.

JULIA, D. A cultura escolar como objeto histórico. Revista Brasileira de História da Educação, n.1, p.09-43, jan./jun. 2001.

LAGE, B. F. Didáctica geral da escola moderna - segundo os atuais programas das escolas do magistério primário. Porto: Edição de J. Reis \& Silvas, 1945.

LIMA, A. Educação e Ensino: educação integral. Lisboa: Guimarães \& Cia., 1914

LOUREIRO, F. S. Lições de pedagogia e didática geral. Edição do Autor, 1950.

LOURENÇO FILHO, M. B. Introdução ao estudo da escola nova. São Paulo: Melhoramentos, 8. ed, 1963.

NÉRICI, I. G. Introdução à didática geral (dinâmica da escola). Brasil/Portugal: Fundo de Cultura, 1960.

NÓVOA, A. Uma educação que se diz nova. In: CANDEIAS, A. et al. (orgs.) Sobre a educação nova: cartas de Adolfo Lima a Álvaro Viana de Lemos. Lisboa: Educa, 1995, p.25-41.

REVISTA ESCOLAR. Edição de setembro de 1926. Órgão da Diretoria Geral da Instrução Pública, São Paulo, 1925 - 1927.

REVISTA ESCOLAR. Edição de fevereiro de 1927. Órgão da Diretoria Geral da Instrução Pública, São Paulo, 1925 - 1927.

REVISTA DE ENSINO da Associação Beneficente do Professorado Público de São Paulo. Edição de julho de 1906. Publicação Bimestral subsidiada pelo Governo do Estado, 1902 - 1918.

SCHRIEWER; J.; NÓVOA, A. A difusão mundial da escola. Lisboa: Educa, 2000.

VIANA, M. G. Pedagogia geral. Porto: Livraria Figueirinhas, 4. ed., 1960.

Recebido em maio 2020.

Aprovado em janeiro 2021. 